\title{
AVALIAÇÃO DA DETERIORAÇÃO DE TIJOLOS POR AEROSSÓIS MARINHOS
}

\author{
Rita de Cássia de Oliveira Barbosa', Giuseppe Cultrone ${ }^{2}$, Carolina Cardell ${ }^{2}$ \\ 1 - Geóloga, 2 - Universidade de Granada \\ ritafsar@gmail.com
}

Resumo: Com o intuito de ampliar conhecimentos sobre a deterioração de materiais construtivos, este trabalho aborda dados e discussões apresentados em monografia (Máster na Universidade de Granada), cuja pesquisa avalia a durabilidade e o grau de deterioração de tijolos em clima costeiro ou zonas sob a influência de aerossóis marinhos. Foi realizado um ensaio de envelhecimento acelerado com uma câmara de spray salino (pulverização de água do mar). A pesquisa foi executada em três etapas: 1a) os tijolos sãos foram caracterizados através de microscopia ótica (luz polarizada) e difração de raios-X (DRX), ensaios físicos (colorimétricos e ultra-som) e ensaios hídricos (absorção e dissorção), porosimetria por injeção de mercúrio (PIM) para analisar o sistema poroso e a distribuição dos poros; 2a) o ensaio de envelhecimento acelerado dos tijolos em câmara de spray salino, onde se aplicou uma variação da norma ASTM-B-117-73; e, 3a) O grau de deterioração dos tijolos foi avaliado com algumas técnicas analíticas utilizadas na primeira etapa, além da microscopia eletrônica de varredura ambiental (ESEM) e a microscopia eletrônica de varredura com pressão variável (VPSEM) para identificar a cristalização de sais. Foram identificados cristais de halita nos planos de exfoliação dos filossilicatos e na superfície dos tijolos, predominando um ataque físico e não químico. Os cristais de halita apresentam hábitos cúbicos e aciculares, resultantes de diferente umidade do substrato, da concentração da solução salina (água do mar) e da variação da umidade relativa. A presença de sais na estrutura dos tijolos contribui para a diminuição da porosidade (preenchimento de determinados poros), assim como para o aumento nos poros de tamanhos 0,1 a 0,01 $\mu$ m. Com base nos resultados obtidos e àqueles já discutidos na literatura, conclui-se que: 1) os ensaios de alteração sob condições ambientais controladas são técnicas de estudo adequadas para análise dos mecanismos de deterioração de tijolos, assim como para os materiais pétreos; 2) a deterioração dos tijolos pode depender da disposição das argilas, da superfície de exposição do mesmo e do arranjo, vertical ou horizontal, destes, na construção; e 3) neste caso específico, os tijolos apresentam boa durabilidade mesmo quando submetidos às intempéries de um clima costeiro.

Palavras Chave: tijolos, aerossóis marinhos, deterioração

Abstract: EVALUATION OF TILES DETERIORATION BY MARINE AEROSOLS. With aim of obtaining deeper knowledge about building materials decay, the present work contains data and discussion presented in a monography (Máster Course). The objective of this work is evaluate the durability and damage of bricks in a coastal environment, on areas that can receive the influence of marine spray. The study was realized by using polarized optical microscopy, x-ray diffraction (XRD), colorimetry, ultrasounds, hydric tests, mercury injection porosimetry (MIP), environmental scanning electron microscopy (ESEM) and variable pression scanning electron microscopy (VPSEM), and the saltspray (sea water) aging test with some variation of the ASTM-B-117-73. Crystals of halite were identified as well in exfoliation planes of the phylosilicates as superficially (physic process preveals the chemical one). The results obtained in this study allow conclude: 1 ) the aging tests under controlled environmental conditions are suitable techniques for the research of mechanism decay in bricks as well as to stone materials (granites, calcareous rocks); 2) the bricks decay can depend on the clay arrangement, itself superficial exposure and their package (vertical or horizontal) in the building; 3 ) in this case bricks present a good durability even though when they are in a coastal environmental undergone.

Keywords: bricks, marine spray, materials decay

\section{INTRODUÇÃO}

\subsection{Definições}

Por definição os tijolos são peças cerâmicas, em geral de forma prismática retangular, com dimensões que costumam ser de $24 \times 11,5 \times 5,25 \mathrm{~cm}$ (KORNMANN \& CTTB, 2007). De acordo com a norma UNE $67019 \mathrm{EX} / 96$, os tijolos devem tener uma dimensão máxima igual ou inferior a $29 \mathrm{~cm}$, e são o resultado do cozimento de um material rico em agila. As arestas dos tijolos são denominadas comprimento, largura e altura. Outra definição (ALLABY e ALLABY, 1999) de tijolo é a de um bloco plano de argila utilizado para construção, geralmente de forma oblata com caras planas e borda paralela, e que apresenta uma textura uniforme sem fissuras, bolhas de ar, ou fragmentos. Preferencialmente, o tipo de argila deve ter baixo conteúdo de água para limitar a contração durante a secagem. De acordo alguns autores os tijolos podem ser considerados como rochas artificiais cozidas ao forno ("metamorfismo industrial", RICCARDI et al., 1999).
Fabbri (1988) apresenta uma classificação com três tipos de tijolos baseada em aspectos mineralógicos e de composição química: 1) materiais cerâmicos silicatados, fabricados com argila ou outros silicatos; 2) materiais cerâmicos com óxidos de tipo simples e complexo; e, 3) materiais cerâmicos com elementos e compostos sem oxigênio. Outra clasificação de tijolos, apresentada no Pliego RL-88 e na norma UNE 67091 EX/96, os diferencia em relação à sua forma em: 1) maciços; 2) perfurados; e, 3) ocos.

De acordo com sua função (CULTRONE, 2001), os tijolos podem ser classificados como: 1) comuns: fabricados em grande escala e utilizados para construção; 2) de fachada: também utilizados para construção, onde se valoriza seu aspecto final; 3) técnicos (ou azules): são mais duros, densos e aplicados na Engenharia Civil; 4) ocos: são mais leves e isolantes térmicos, utilizados em paredes; e, 5) vitrificados: recibem uma vitrificação branca e são usados de acordo com a necessidade. $\mathrm{Na}$ construção, a união dos tijolos com argamassas chama-se arranjo, de modo que existe uma grande variedade de combinações possíveis. Os arranjos 
servem para estipular as dimensões dos muros, de maneira que sejam construídos homogeneamente. Os tijolos são fabricados a partir de material argiloso que varia de argilas não litificadas a rochas argilosas, assim como argilitos e até algumas ardosias, e submetidos a cozimento (CULTRONE, 2006).

Desde a pré história o homem descobriu a utilidade da argila para produzir seus utensílios domésticos, da mesma forma que suas edificações a partir da taipa, adobe e tijolo, quando adquiriu a técnica de cozimento da peça (CULTRONE, 2001). O que constitui um material cerâmico são (CULTRONE, 2006): 1) matriz (material plástico): com fração mais fina, constituída por minerais de sílice, silicatos e aluminosilicatos, e uma mais grossa, formada por distintas proporções de quartzo, mica, calcita, dolomita, feldespatos e geso. Em menores quantidades pode haver pirita, siderita e magnetita, assim como matéria orgânica e sais solúveis; 2) desengordurantes, que diminui a plasticidade da cerâmica, evita retrações e reduz tempo de secagem. Em general trata-se de sílice, quartzo, feldespato, chamota (restos cerâmicos) e, algumas vezes, calcita; 3) fundentes, para baixar o ponto de fusão, constituídos por: carbonatos, sulfatos e boratos sódicos, feldespatos potásicos e sódicos; 4) corantes e revestimentos: vernizes e esmalte.

O adobe é o tijolo seco ao sol em geral está composto por barro, areia, geso e vários aditivos, que poderiam ser impurezas mineralógicas e orgânicas. A areia ajuda a controlar a contração dos poros durante a secagem. Areias grossas e angulosas costumam ser melhores que aquelas mais finas ou arredondadas. Palha e cal acrescentadas ao adobe não lhes dão mais resistência, porém aceleram sua secagem e reduzem sua contração impidindo a formação de gretas (BOUDREAU, 1971).

\subsection{Deterioração}

De um modo geral, a deterioração dos materiais pétreos em monumentos é o resultado de: 1) dissolução química; 2) desagregação mecânica como consequência do congelamento da água nos poros; 3) abrasão por partículas do vento; 4) exfoliação em virtude do rápido aquecimento y resfriamento; 5) desagregação resultado da atividade orgânica; 6) formação de cristais na superfície; e, 7) danos causados por intervenções de conservação e restauração imprudentes (RAPP, 2002).

É evidente que a cerâmica sofre processos de deterioração pelos mesmos agentes que atuam nos materiais pétreos. Observou-se que a deterioração acelerada dos tijolos existem causas externas, como, por exemplo: cristalização de sais, umidade, frieza e atmosfera contaminada; e também pode estar relacionado com a matéria prima utilizada no proceso de fabricação. Assim, pode ocorrer fraturamento se o tijolo contem grãos de carbonato superiores ou iguais a $1 \mathrm{~mm}$, e o aumento das dimensões do tijolo por captação de umidade ambiental (CULTRONE, 2006).

\subsection{Contextualização}

Os sais solúveis são conhecidos por causar deterioração nos materiais porosos em ambientes muito diversos, desde desérticos a áreas costeiras (EVANS, 1969; CHAROLA, 2000; DOEHNE, 2003). As formas de alteração originadas podem ser desagregação granular (LARSEN, 2007) e em casa de abelha conhecidos como "honeycomb weathering". Além disso, pode formar descamação em colunas e paredes (CHABAS et al., 2000). Em relação aos mecanismos de alteração por aerossóis marinhos alguns autores relatam a influência da taxa de evaporação, umidade relativa e o padão de cristalização dos sais nestes mecanismos (KUCHITSU et al., 1999; RODRÍGUEZ-NAVARRO e DOEHNE, 1999, p. 197; LUBELLI et al., 2003; CARDELL et al., 2003; GOMEZ-HERAS e FORT, 2007, p. 265).

Lubelli et al. (2003), analisando os tijolos da igreja de Dumburg na área costeira da Nova Zelândia, enfatizaram que a deterioração causada pelos sais marinhos nos materiais porosos de construção não se produzem somente nas regiões costeiras, mas também nas áreas continentais. Segundo os autores supracitados, em uma mesma parede da igreja identificaram-se dois tipos de danos: 1) na parte superior uma desagregação en forma de pó resultado da cristalização de cloreto de sódio; e, 2) na parte inferior a formação de vesículas pela cristalização de geso na capa superficial do tijolo.

Carolina Cardell et al (2003, p. 3), em rochas graníticas e calcáreas, e Rivas et al (2003, p. 427), em rochas graníticas, realizaram ensaios de envelhecimento acelerado em câmara de spray salino, utilizando em ambas pesquisas uma solução de cloreto de sódio e outra com água do mar. O ensaio simulava as condições ambientais costeiras com temperatura compreendidas entre 35 e $39{ }^{\circ} \mathrm{C}$ e umidade relativa de 50\%, comn objetivo de comparar as morfologias de deterioração desenvolvidas pela cristalização dos sais sob condições similares de ensaio em cada tipo de rocha.

Esta pesquisa teve como objetivo principal avaliar o efeito do ambiente costeiro na durabilidade de tijolos maciços através de ensaio de envelhecimento acelerado em câmara de spray salino. Foram avaliadas e caracterizadas as mudanças mineralógicas, texturais e estruturais ocasionados nos tijolos estudados pela ação dos sais solúveis presentes na água de mar utilizada. Os resultados deste estudo proporcionaram uma informação essencial para a preservação, 
restauração e manutenção dos edifícios históricos construídos com este tipo de material, situados em zonas costeiras ou que recebam sua influência. Para a obtenção dos dados foram realizados estudos mineralógicos, petrográficos e físico-químicos nos tijolos antes e depois de submetê-los ao aerossol marinho no laboratorio.

\section{MATERIAIS E MÉTODOS}

Foram selecionadas 22 amostras de tijolos pertencentes ao acervo do Departamento de Mineralogia e Petrologia da Universidade de Granada (UGR). Estas peças apresentam dimensões aproximadas de $2 \times 3 \times 5 \mathrm{~cm}$ e cor laranjaavermelhada, foram cozidas em forno elétrico em atmosfera oxidante a $\mathrm{T} \approx 950^{\circ} \mathrm{C}$ (CULTRONE, 2001).

Foram utilizadas varias técnicas analíticas, na primera etapa caracterizaram-se os aspectos mineralógicos e petrográficos dos tijolos sãos através de microscopia óptica polarizada e difração de raios $X$ (DRX). Foram também realizados ensaios físicos (colorimetria e ultrasom) e ensaios hídricos (absorção e desorção de água). Para analizar o sistema poroso e distribuição de poros utilizou-se porosimetria por injeção de mercúrio (PIM) (Figura 1) (CULTRONE, 2001).

$\mathrm{Na}$ segunda fase, onde as amostras foram submetidas ao ensaio de envelhecimento acelerado em câmara de spray salina, utilizou-se água do mar. A mesma foi analisada antes de iniciar o ensaio: os cátions analisados por Espectroscopia de Absorção (AAS) e Emissão Atômica (EMS), e os ânions por cromatografia líquida de ânions (HPLC). $\mathrm{O} \mathrm{pH}$ determinou-se o equipamento CRISON MICROpH 2001 calibrado com soluções padrões de $\mathrm{pH}=4 \mathrm{e} \mathrm{pH}$ $=7$.

Na terceira etapa foram avaliados os efeitos do processo de alteração em câmara salina utilizandose quase as mesmas técnicas aplicadas para os tijolos sãos. Para observação da presença de sais na estrutura dos tijolos utilizaram-se a microscopia electrônica de varredura ambiental (ESEM) e a microscopia electrônica de varredura com pressão variável (VPSEM) (Figura 1).

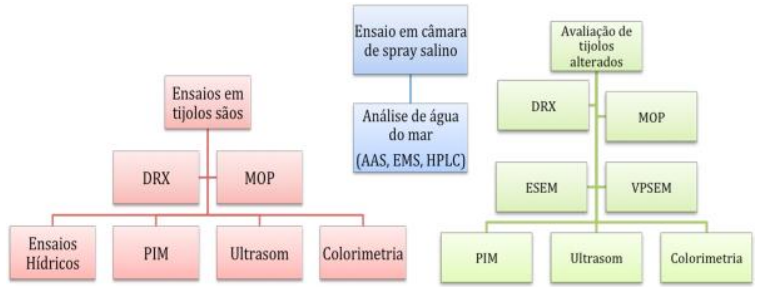

Figura 1. Esquema metodológico das técnias aplicadas na pesquisa de deterioração de tijolos por aerossóis marinhos. (Modificado de BARBOSA, 2008, p. 14)

\section{ENSAIO EM CÂMARA DE SPRAY SALINO}

Para o ensaio de envelhcimento acelerado por aerossóis marinhos foi utilizada uma câmara de corrosão de spray salino INELTEC (Figura 2) (Laboratório de Mecânica dos Solos do Departamento de Construções Arquitetônicas da Escola de Arquitetura Técnica da UGR). As 6 amostras de tijolos selecionadas para os ensaios hídricos, de ultrasom, medidas de colorimetria, foram submetidas para o ensaio de envelhecimento acelerado em câmara salina. Empregou-se uma variação da norma de corrosão ASTM-B-117-73 uma vez que foram realizados dois ensaios: um com ciclos de pulverização continua e outro com ciclos de pulverização e seco. Em ambos os casos utilizou-se spray marinho na câmara salina sob condições atmosféricas controladas, no lugar de uma solução salina à base de $\mathrm{NaCl}$, como se indica a norma, ao considerar que o spray marinho é mais representativo dos aerossóis costeiros.

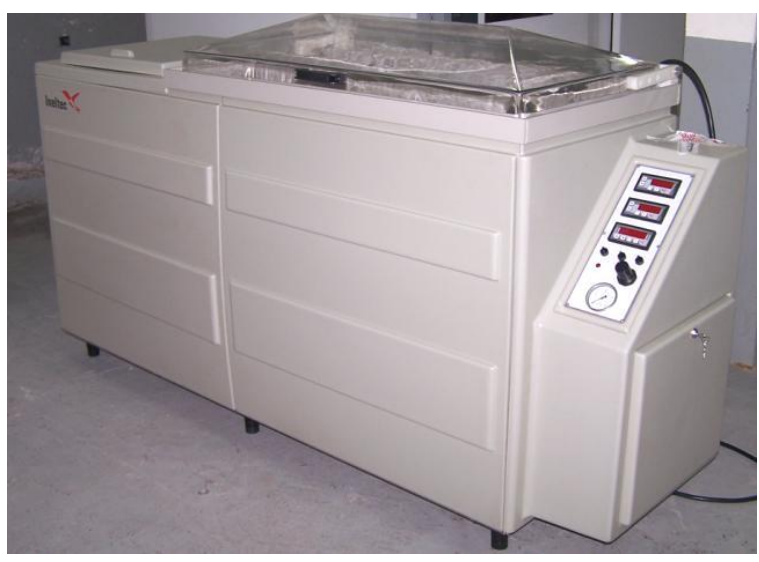

Figura 2. Câmara de corrosão de spray salino (INELTEC).

O primeiro ensaio de pulverização contínua durou 65 dias e foiram realizafos 350 ciclos com umidade relativa constante (U.R. = 70 $\pm 5 \%$ ), temperatura de 35 으 dentro da cámara (TCam). No segundo ensaio as condições de temperatura da câmara foram mantidas, porém a umidade relativa foi de $35 \pm 5 \%$, no período de seco, e $70 \pm 5 \%$, no período de pulverização. Totalizaram 41 ciclos em 20 dias. A Tabela 1 apresenta os resultados da análise química da água do mar utilizada para o ensaio. As amostras foram pesadas no início e no final do ensaio. Posteriormente foram feitas análises no VPSEM e ESEM, e de DRX.

Tabela 1. Composição, em ppm, e pH de água do mar utilizada no ensaio de cristalização de sais em câmara de spray salino (Praia de Salobreña, sul da Espanha).

\begin{tabular}{cccccccc}
\hline $\mathrm{Cl}^{-}$ & $\mathrm{SO}_{4}{ }^{2-}$ & $\mathrm{NO}_{3}{ }^{-}$ & $\mathrm{Na}^{+}$ & $\mathrm{Ca}^{2+}$ & $\mathrm{K}^{+}$ & $\mathrm{Mg}^{2+}$ & $\mathrm{pH}$ \\
\hline 12879 & 5692 & 148,80 & 10030 & 330 & 348,40 & 1069 & 7,84 \\
\hline
\end{tabular}




\section{RESULTADOS E DISCUSSÕES}

\subsection{Características Mineralógicas e Texturais}

4.1.1. Difração de Raios X (DRX) e Microscopia óptica de polarização (MOP)

Os resultados obtidos em tijolos sãos permitiram identificar as fases minerales: quartzo, feldspato, hematitas, ilita/muscovita e talco (Figura 3). Trata-se de uma mineralogia bastante comum em peças de tijolo cozido. A presença de filossilicatos é indicativa de uma temperatura de cozimento não elevada (CULTRONE et al., 2001).

Os tijolos, sob microscópio petrográfico (luz polarizada) apresentam os mesmos minerais detectados por DRX, isto é, fragmentos de quartzo, plagioclásio e óxidos de ferro, todos eles imersos em uma matriz argilosa (Figura 4). Texturalmente, a matriz apresenta uma certa orientação evidenciada sobretudo por cristais laminares (filossilicatos). Esta orientação possivelmente é resultado da compressão realizada durante a fase de modelamento dos tijolos.

Os fragmentos de quartzo apresentam tamanhos heterogêneos e são o angulosos. Todavia, em alguns casos se reconhece sua textura en mosaico e extinção ondulante, característica típica do quarzo metamórfico. Os minerais argilosos e as micas apresentam hábito lamelar e cor de interferência que não supera a primeira ordem. É possível que o cozimento destas peças cerâmicas tenha causado uma diminuição da birrefringência dos filossilicatos. Pode ser que a ilita/muscovita tenha sofrido um processo de transformação que levou a sua heshidroxilação generando pequenos cristais de mulita (AI6Si3015) (GRAPES, 1986, CLARK e PEACOR, 1992). Ainda que não se encontre evidência da presença deste silicato de aluminio por DRX nem por MOP.

Em menor quantidade e em cristais menores que o quartzo e os cristais de plagioclásio são os minerais opacos, de mesma cor marron avermelhado que a matriz, de modo que se confunde com ela. Possivelmente trata-se de óxidos de ferro, como a hematita que foi identificada por DRX. Entre os minerais acessórios identificou-se somente o zircão.

Durante os ensaios de alteração em câmara de spray salino, não se observaram grandes mudanças macroscopicamente, porém, uma vez finalizado o experimento, comprovou-se um pequeno ganho de massa (Tabela 2). As amostras de tijolo penduradas horizontalmente dentro da câmara salina apresentam um discreto aumento de massa quando comparada àquelas penduradas verticalmente.

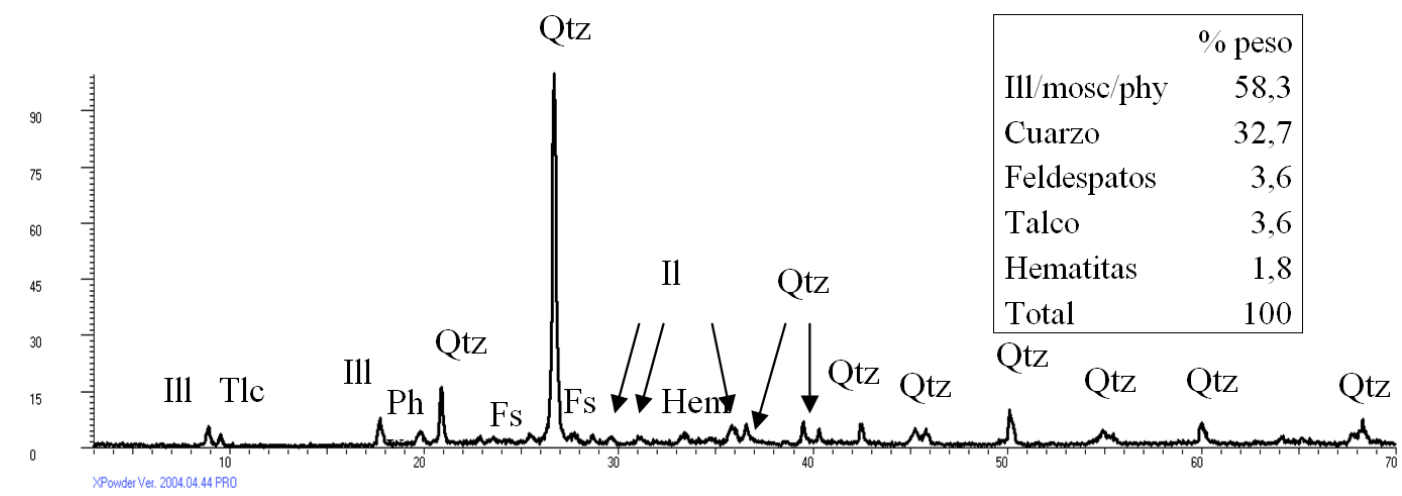

Figura 3. Diagrama de difracción de raios X e análisis semi quantitativo para amostras de pó de tijolos sãos (BARBOSA, 2008, p. 23).

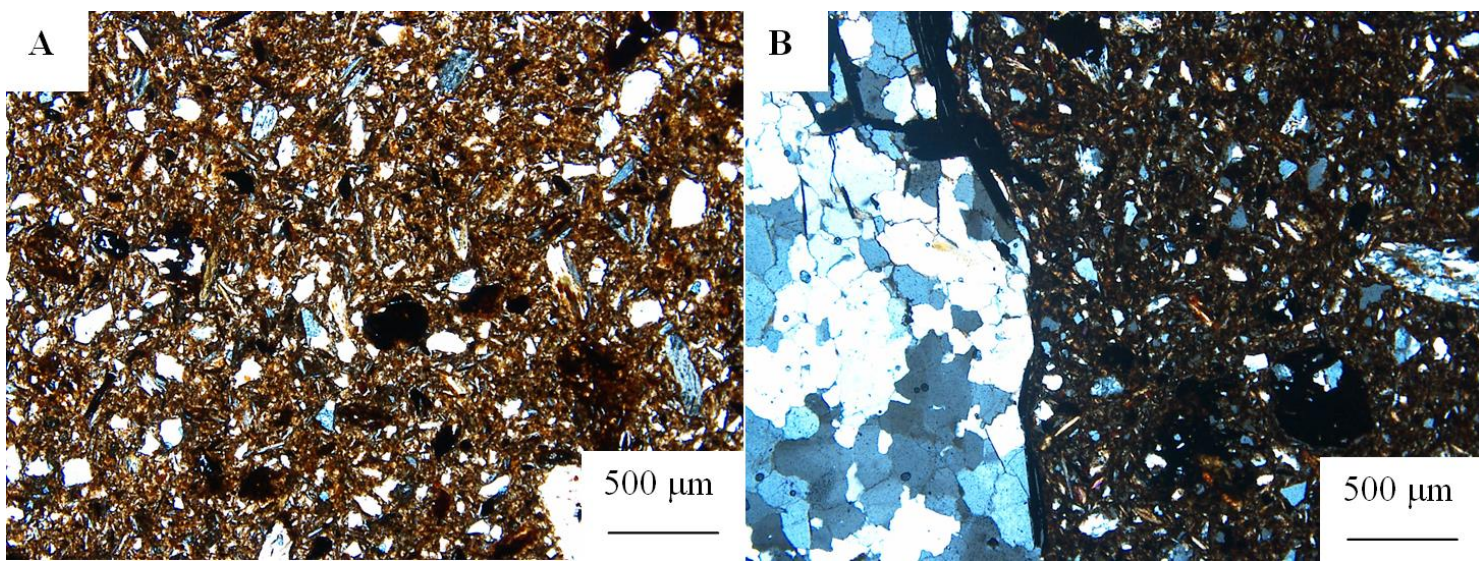

Figura 4. Aspecto sob microscópio óptico do tijolo são: A) fragmentos angulosos de quartzo em matriz argilosa (luz transmitida LN); e B) fragmento de quartzo com textura en mosaico (luz transmitida NX) (BARBOSA, 2008, p. 24). 
De um modo geral, no terceiro dia de ensaio observaram-se nas amostras algumas eflorescências. Nos tijolos pendurados horizontalmente essas eflorescências eram mais evidentes e os sais cristalizaram preferencialmente na parte superior do tijolo (Figuras 5a, b e c). 0 hábito dos cristais em geral eram cúbicos, também foi possível visualizar de modo isolado, em algumas arestas, cristais alongados, com hábito fibroso, correspondentes a cristais "whiskers muito finos" (crescem em uma superfície seca onde há presença de solução de modo localizado) (ZEHNDER e ARNOLD, 1989; ARNOLD et. al., 1990; CARDELL, 1998). Para os tijolos pendurados verticalmente as observações são muito similares àquelas apresentadas para os tijolos horizontais em relação ao hábito dos cristais, porém sua cristalização realizou-se na parte superior dos tijolos (Figuras 6a, b e c). Durante os dois ensaios de alteração não foi registrada nenhuma desagregação dos tijolos.
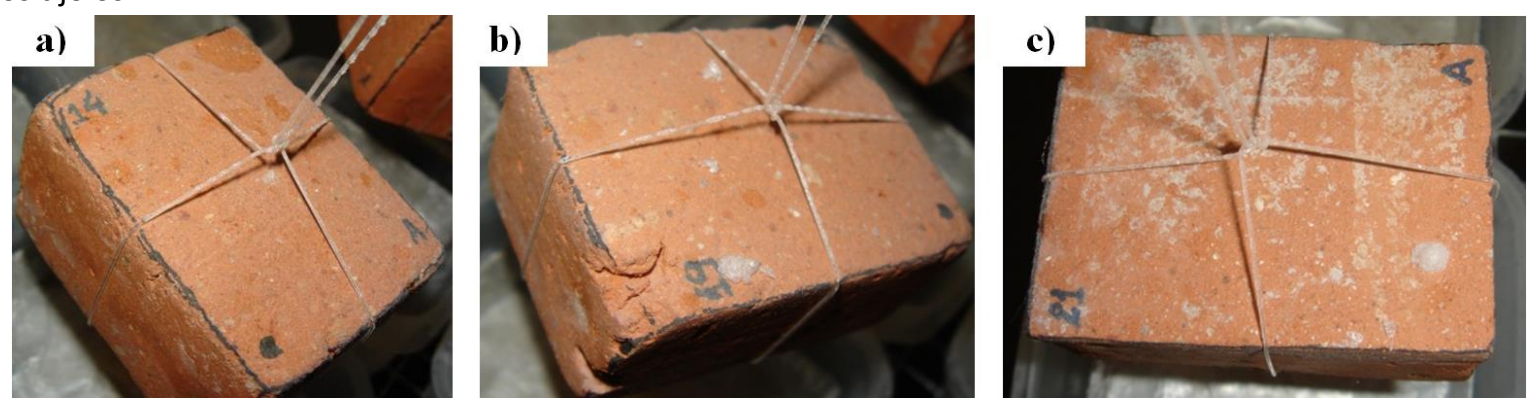

Figura 5. Tijolos pendurados horizontalmente dentro da câmara de spray salino: a) Lad-14 (2ensaio), b) Lad-19 e c) Lad-21 (1ํ ensaio) (BARBOSA, 2008, p. 31).
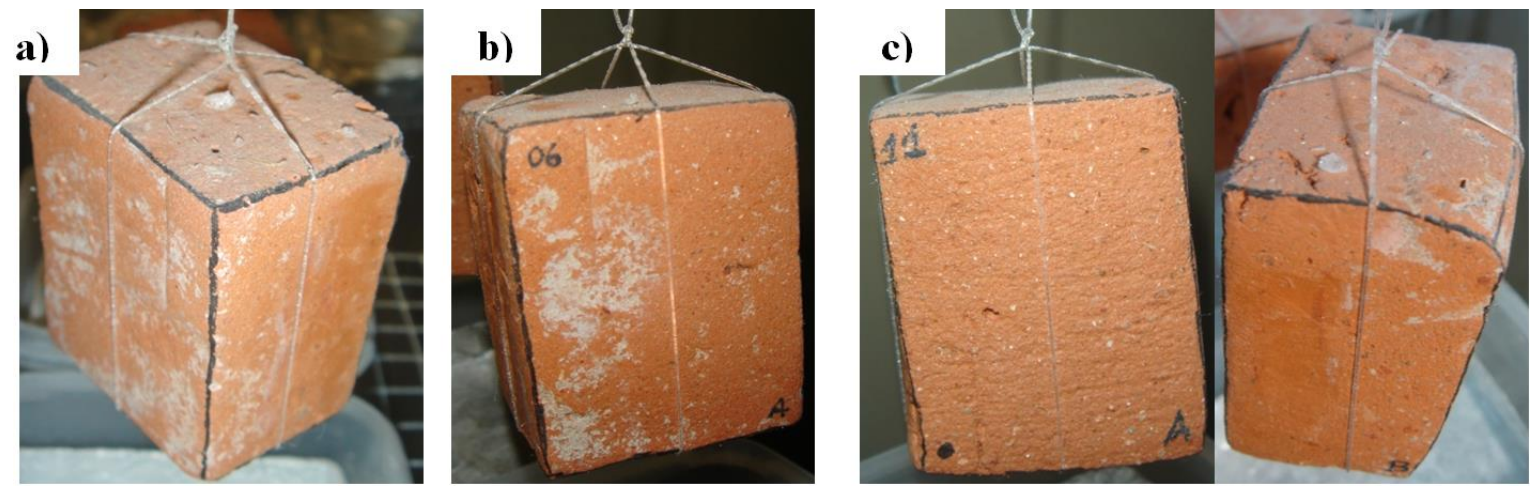

Figura 6. Tijolos perdurados verticalmente apresentam cristalização de sais preferencialmente na parte superior: a) Lad-03, b) Lad-06 e c) Lad-11 (BARBOSA, 2008, p. 31).

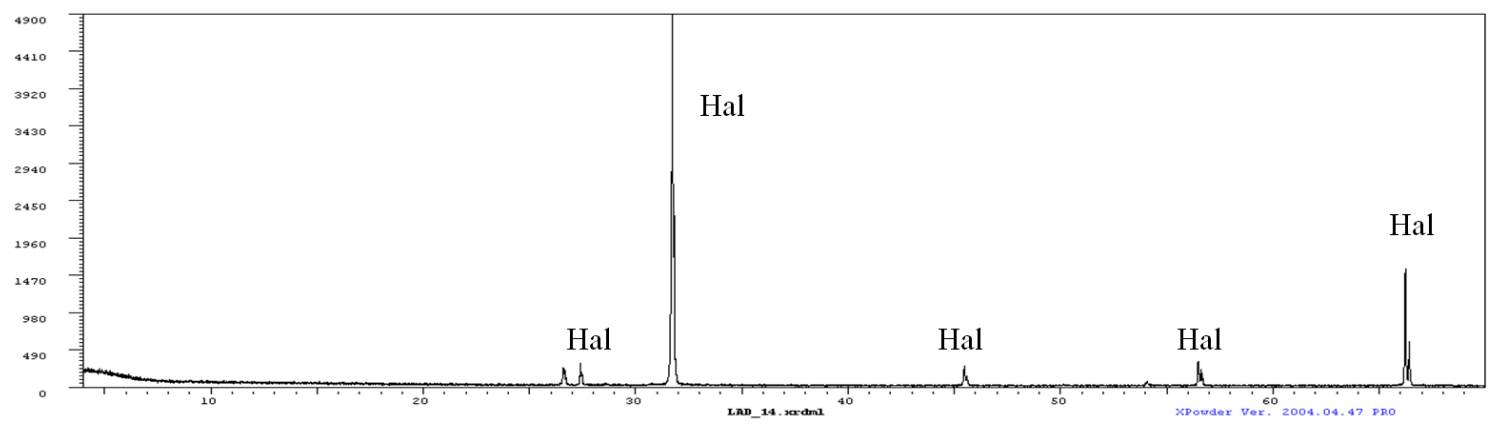

Figura 7. Difratograma obtido para sais de tijolos submetidos aos ensaios de alteração. 


\subsubsection{Microscopia Eletrônica}

A observação ao microscópio óptico das lâminas delgadas dos tijolos depois dos ensaios de alteração (pulverização contínua e pulverização alternada com seco em câmara salina) não revelou mudanças substanciais na textura das amostras. Entretanto, mediante microscopia electrônica de varredura ambiental (ESEM) e de varredura com pressão variável (VPSEM), observou-se o desenvolvimento de cristais de halita na superfície e no interior, sobre todo nos planos de exfoliação dos filossilicatos (BARBOSA, 2008, p. 35).

Na técnica de VPSEM é possível observar, em detalhe, o hábito cúbico dos cristais de cloreto de sódio, principalmente na superfície das amostras de tijolo alteradas no primeiro ensaio (Figuras 8a e b). Observam-se unicamente cubos de halita (forma de equilíbrio), alguns com um orifício na parte central (forma cristalina denominada "hopper").

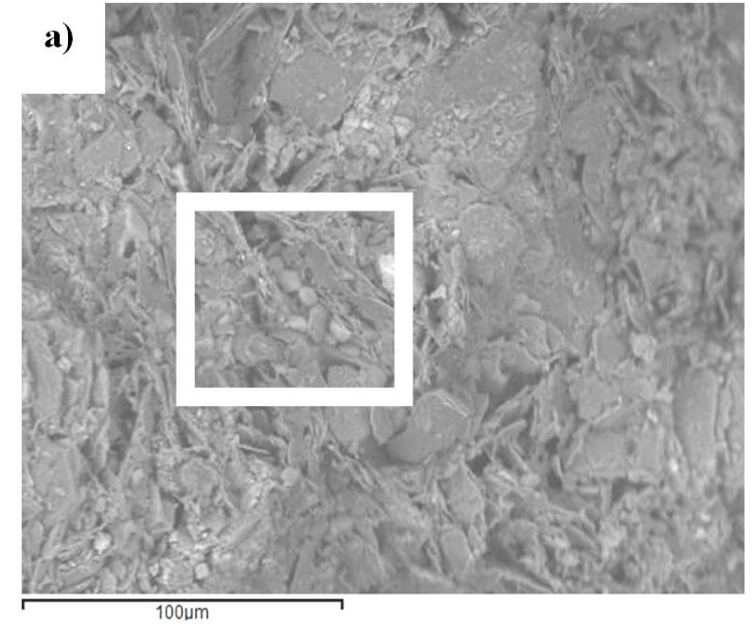

Utilizando-se a técnica ESEM confirma-se o maior desenvolvimento dos cristais de halita na superfície destes tijolos alterados, e é mais evidente a orientação linear dos cubos de $\mathrm{NaCl}$ nas superfícies de exfoliação dos filossilicatos (Figuras 9a e b). Portanto as zonas onde concentram-se os filossilicatos nos tijolos são "pontos débis" por onde se inicia a deterioração dos mesmos ao favorecer ai a precipitação de halita.

Para as amostras de tijolos submetidas ao segundo ensaio de alteração as observações ao ESEM revelam que o crescimento de cristais de cloreto de sódio é parecido ao ocorrido no primeiro ensaio. Não obstante, a forma de crescimento dos sais é um pouco distinta, em alguns casos os cristais de halita apresentam-se com hábito cúbico com orifícios na parte central (cristal "hopper"), e em outros as faces estão escalonadas, além destes formaram-se cristais aciculares (Figuras 10a, b e c).

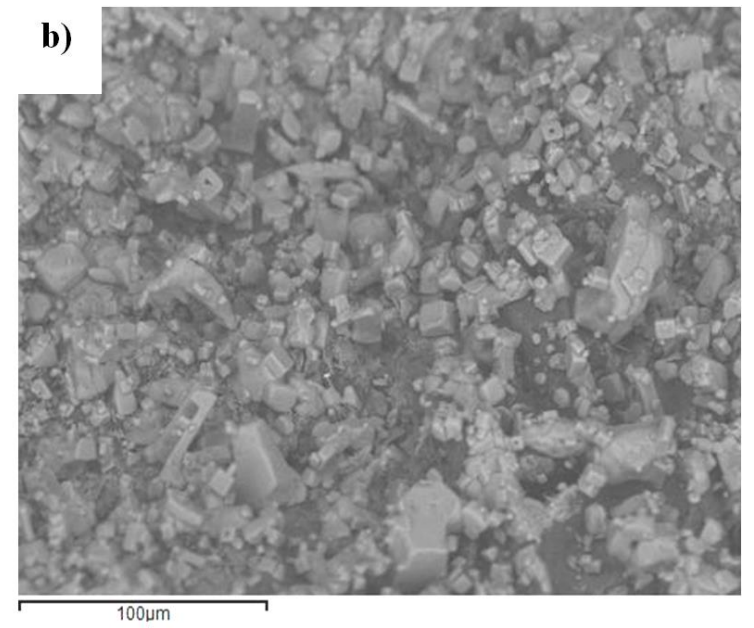

Figura 8. Microfotografías ao VPSEM de cristais cúbicos de halita em tijolos alterados: a) nos planos donde localizam-se as argilas e b) dispersos na superfície do tijolo.
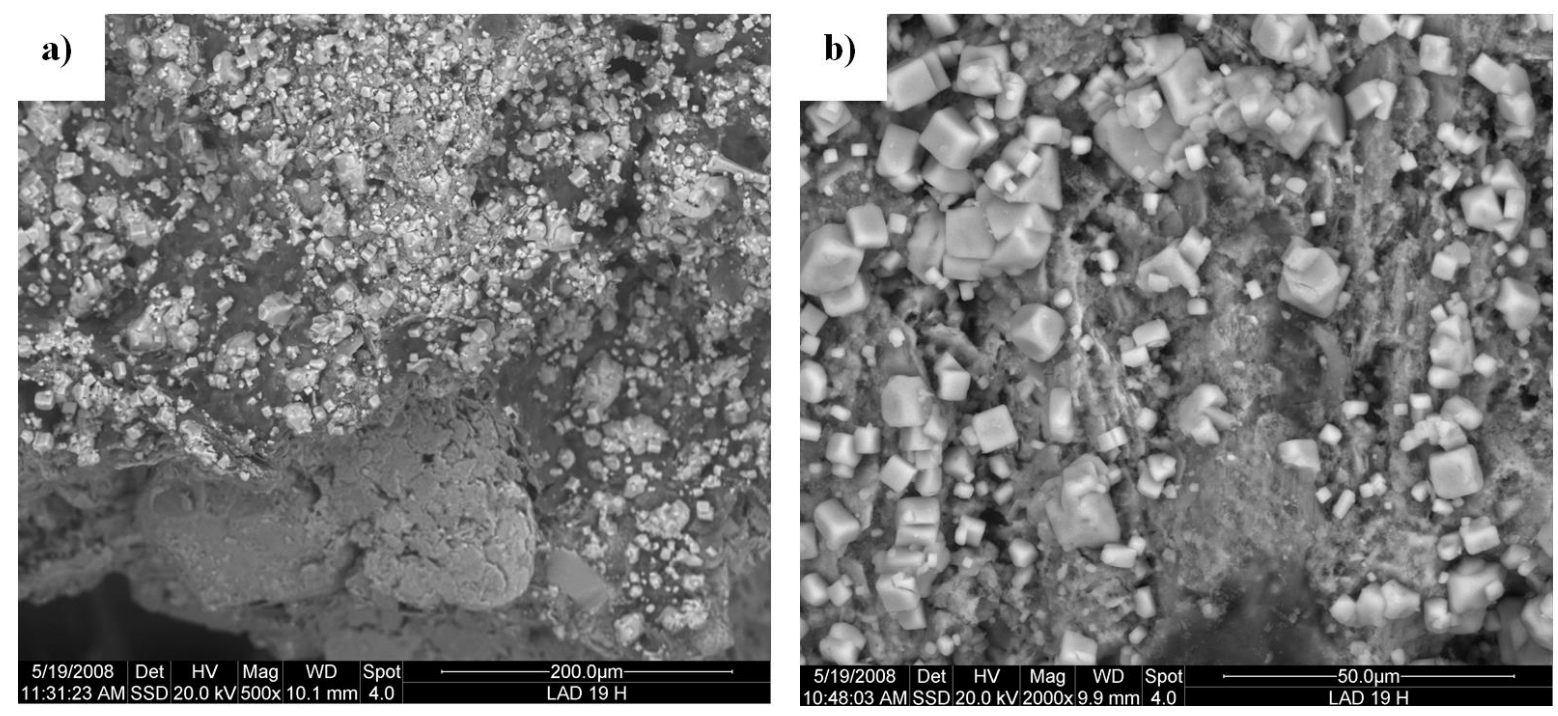

Figura 9. Aspecto dos cristais de NaCl em tijolos alterados da observação ao ESEM com elétrons retrodispersados (primeiro ensaio): a) contraste entre a parte superficial alterada do tijolo e a parte mais interna sem cristais e b) os cristais crescem entre os planos dos 


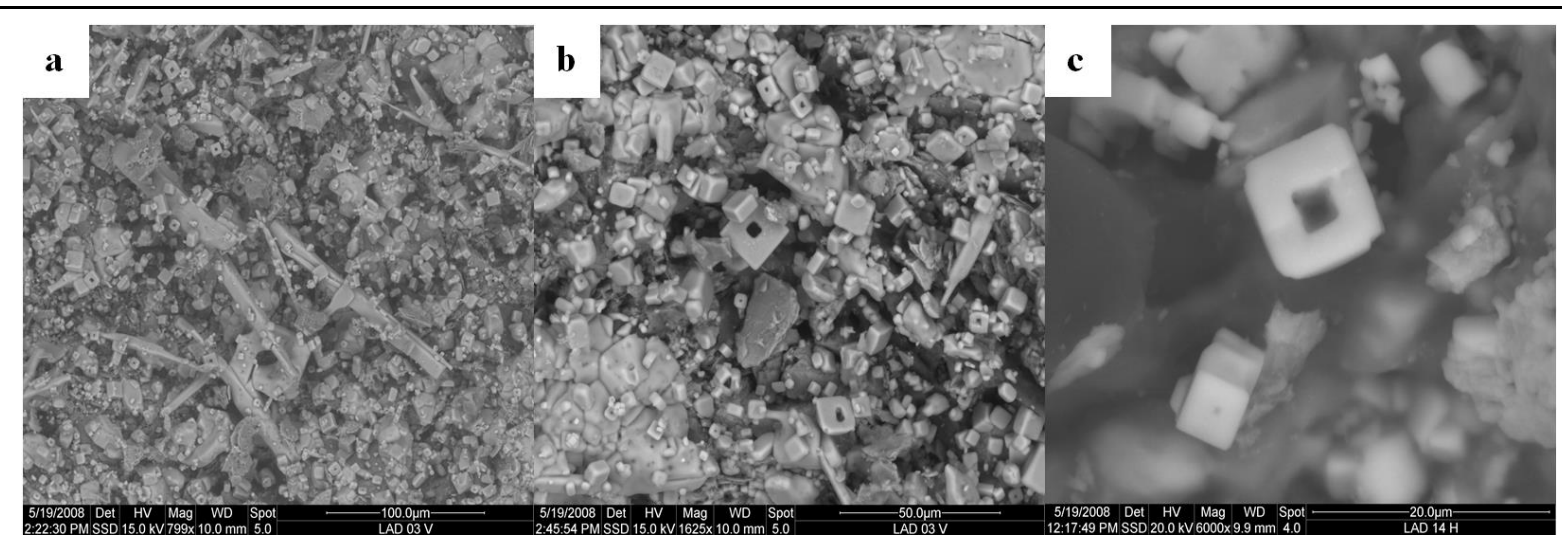

Figura 10. Cristais de $\mathrm{NaCl}$ em tijolos alterados: a) Cristales cúbicos e aciculares, b) Cristais cúbicos isolados e agregados e c) detalhe de cristais cúbicos (Hopper) (BARBOSA, 2008, p. 37).

Os cristais prismáticos de halita podem ser resultado de uma cristalização sob condições de U.R. baixa, de 35 $\pm 5 \%$ (RODRÍGUEZ-NAVARRO e DOEHNE, 1999, p.199): este foi o porcentual de umidade relativa alcançado no período de seco do segundo ensaio (na câmara de spray salino). A variação da umidade relativa pode explicar a formação dos dois tipos de cristais de halita, uma vez que o hábito dos sais está relacionado com a umidade do substrato, e assim com a concentração de sal precipitado (ARNOLD et al., 1990 e CARDELL, 1998).

\subsection{Características Físicas}

\subsubsection{Ensaios Hídricos}

Como apresentado do fluxograma da Figura 1, o Ensaio Hídrico foi realizado somente para tijolos sãos. Estes apresentam uma absorção livre média de 20,03\% e um coeficiente de absorção médio de 0,1508 (Tabela 3). Na figura 11a e b, representam-se as curvas de absorção e desorção livre de água determinadas para os tijolos. Pode-se observar como as amostras apresentam uma rápida absorção nos primeiros minutos. Depois este aumento tornase mais linear até alcançar o valor máximo de absorção. Debe-se notar na desorção diferentes estágios nas curvas que correspondem a diferentes etapas na secagem, denominadas como "constant" e "falling drying rate" (OTHMER, 1978 e SCHERER, 1990). Finalmente, indicar que algumas curvas ao finalizar o ensaio passam abaixo do zero. Isto significa que durante $o$ ensaio perderam-se pequenos fragmentos do material.

Tabela 3. Valores de absorção livre (AL) e coeficiente de absorção (Ca) para tijolos sãos.

\begin{tabular}{|c|c|c|c|c|c|c|}
\hline & LAD-03 & LAD-06 & LAD-11 & LAD-14 & LAD-19 & LAD-21 \\
\hline AL (\%) & 20,61 & 20,24 & 19,32 & 19,13 & 20,92 & 19,95 \\
\hline $\mathrm{Ca}$ & 0,1467 & 0,1447 & 0,1408 & 0,1464 & 0,1715 & 0,1547 \\
\hline
\end{tabular}

\subsubsection{Porosimetria por Injeção de Mercúrio (PIM)}

Através do ensaio de porosimetria por injeção de mercúrio observou-se que os tijolos apresentam uma distribuição porosimétrica unimodal, e uma concentração máxima de poros próximo ao valor de
$1 \mu \mathrm{m}$. A media da porosidade total aberta dos tijolos (medida sobre duas amostras) é de 40,15\% (Figura 12).
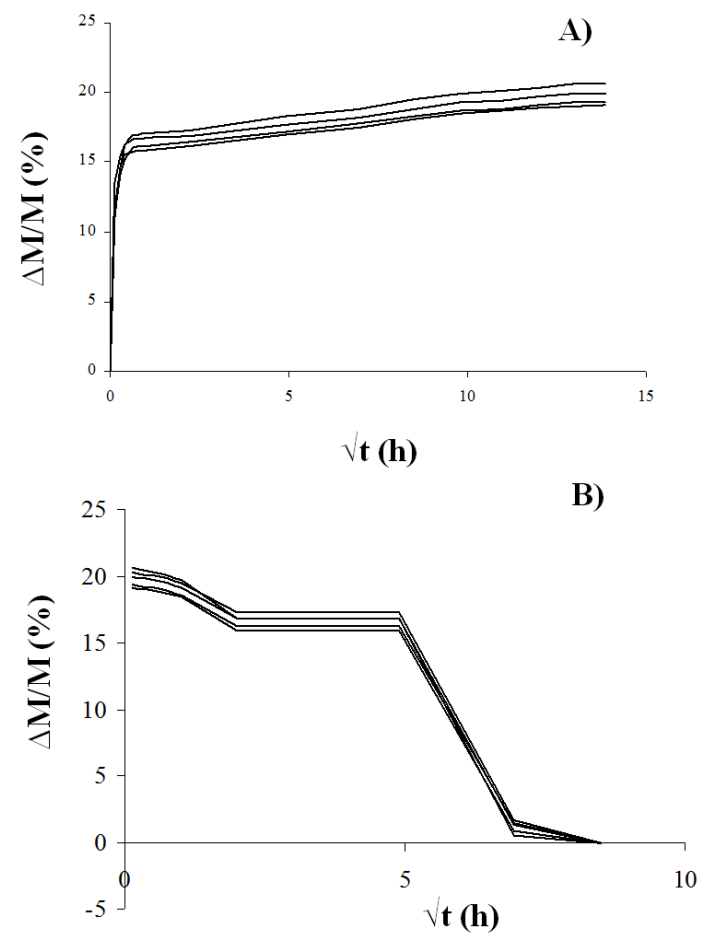

Figura 11. Curva de absorção livre de água versus tempo $(v t)(A) e$ curva de desorção versus tiempo $(v t)(B)$ em tijolos sãos.

Esta técnica foi utilizada para analizar os tijolos submetidos ao primeiro e segundo ensaio de alteração. As amostras foram levadas para ensaio com os sais presentes em seu interior, e otras lavadas com água destilada para evaluar o espacio ocupado y generado por eles. As amostras não lavadas e submetidas ao primeiro ensaio de alteração (pulverização constante) apresentam uma porosidade aberta de $28,98 \%$ (Figura 13a). Isto significa uma diminuição da porosidade aberta de $27,82 \%$ comparada com os tijolos sãos ( $\pm 40,15 \%$ ) (Figura 12). Observa-se um aumento nos poros com tamanho compreendido entre $1,0-0,1$ e 0,1-0,01 $\mu \mathrm{m}$. Na amostra de tijolo lavada (Figura 13b), a 
porosidade é de $37,43 \%$, o que equivale a uma diminuição de 6,74\% comparada ao valor de 40,15\% obtido para tijolo são. Neste ensaio o esperado seria um valor de porosidade mais elevado que aquele obtido para os tijolos sãos, entretanto é possível que os sais presentes não tenham sido eficazmente eliminadas durante o período de lavado, existe constância de casos nos quais os sais cristalizados permanecem no substrato poroso ainda que este tenha sido tratado con água. Tal é o caso de algumas lâminas delgadas elaboradas com água, e nas que persistem sais, particularmente de $\mathrm{NaCl}$. Assim puede justificar-se a presença de sais nos tijolos depois de "lavado".

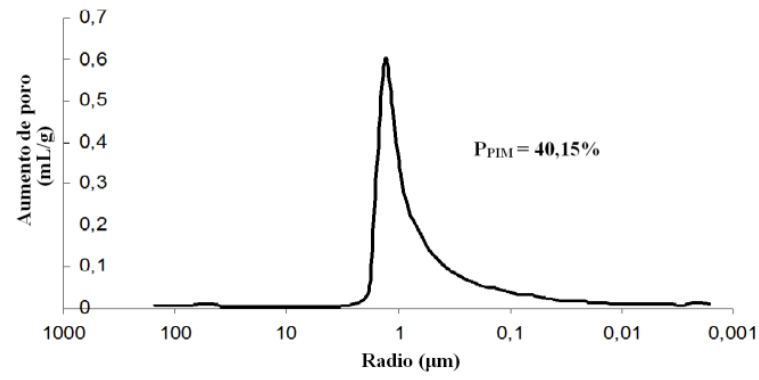

Figura 12. Curva de distribuição de raio de acesso de poros medidos em tijolos sãos.

As amostras submetidas ao segundo ensaio de alteração (pulverização + secado) apresentam, no caso daquelas analizadas com sais, uma porosidade del 38,52\% (Figura 14a); isto é, há uma diminuição de $4,06 \%$ em relação à amostra sã. Para a amostra lavada obteve-se uma porosidade de $42,90 \%$, que corresponde a um aumento de 6,85\%, em relação à porosidade aberta obtida para tijolo são (Figura 14b). Comparando os dois ensaios de envelhecimento acelerado, este último foi mais danoso e os tijolos permaneceram mais deteriorados. Com efeito, as amostras estavam sob condições de umidade relativa variável, e favoreceu uma cristalização mais acentuada dos sais na superfície e interior dos tijolos. Neste segundo ensaio também observou-se um aumento nos poros de tamanhos no intervalo compreendido entre 0,1 e $0,01 \mu \mathrm{m}$. Assim, formara-se poros de tamanhos menores que, por sua vez, favoreceram ao deterioro.

\subsubsection{Ultrasons}

Na tabela 4 são apresentados os resultados das medidas de ultrasons realizadas nos tijolos sãos. Os valores mais altos calculados são aqueles medidos segundo a dirección VB, seguidos de VC e por último VA. A amostra de tijolo LAD-06 constitui uma exceção uma vez que todos seus valores são diferentes dos demais. Os valores de anisotropia total $(\Delta M)$ variam de 17,09 a $33,83 \%$, e os de anisotropia relativa $(\Delta \mathrm{m})$ de 6,37 a $25,44 \%$. Estes valores estão relacionados com a anisotropia em relação à face das amostras de tijolo, isto é com a orientação lamelar desenvolvida pelos filossilicatos das argilas durante a fabricação das peças. Os resultados obtidos para as velocidades de propagação de ultrasons apresentam estreita relação com as características anisotrópicas do material analisado, neste caso do tijolo.
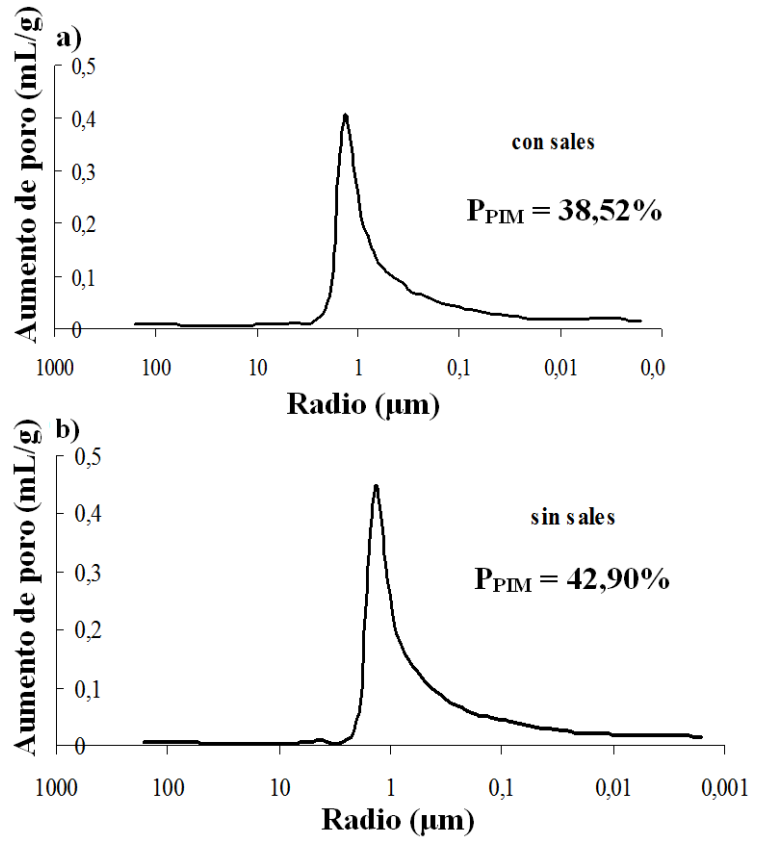

Figura 13. Curva de distribuição porométrica para tijolos alterados no primeiro ensaio: a) com sais presentes e b) lavados em água destilada.

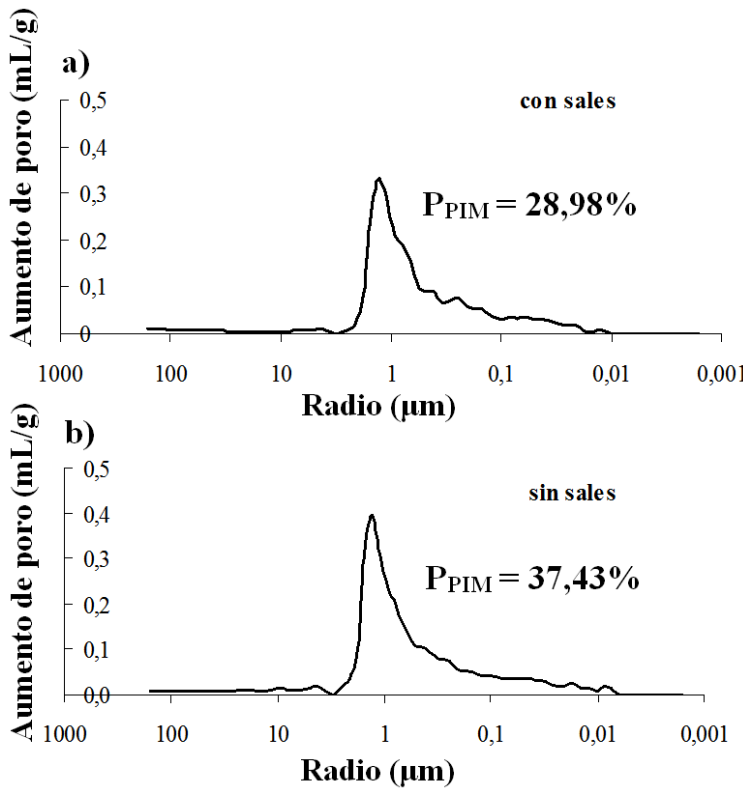

Figura 14. Curva de distribuição porométrica para tijolos alterados no segundo ensaio: a) com sais presentes e b) lavados em água destilada. 
Tabela 4. Velocidades de propagação de ultrasons (em $\mathrm{m} / \mathrm{s}$ ) obtidas para as três direções perpendiculares entre si das seis amostras de tijolo seleccionadas (VA - velocidad para tabla; VB velocidad para canto; VC - velocidad para testa; $V m$ - velocidad media para cada ladrillo; $\Delta M$ - anisotropía total; $\Delta m$ - anisotropía relativa).

\begin{tabular}{|c|c|c|c|c|c|c|}
\hline Muestras & $\mathrm{V}_{\mathrm{A}}$ & $\mathrm{V}_{\mathrm{B}}$ & $\mathrm{V}_{\mathrm{c}}$ & $\mathrm{V}_{\mathrm{m}}$ & $\mathbf{\Delta M}$ & $\mathbf{\Delta} \mathrm{m}$ \\
\hline LAD-03 & 1264,57 & 1745,45 & 1440,11 & 1483,38 & 20,61 & 19,17 \\
\hline LAD-06 & 1378,50 & 1609,76 & 1715,69 & 1567,98 & 17,09 & 6,37 \\
\hline LAD-11 & 1128,91 & 1854,55 & 1557,47 & 1513,64 & 33,83 & 17,41 \\
\hline LAD-14 & 1302,75 & 1920,40 & 1574,07 & 1599,07 & 25,44 & 19,82 \\
\hline LAD-19 & 1207,21 & 1791,30 & 1387,01 & 1461,84 & 24,03 & 25,44 \\
\hline LAD-21 & 1276,50 & 1815,53 & 1590,21 & 1560,75 & 25,04 & 13,23 \\
\hline
\end{tabular}

Este estudo foi realizado durante 28 dias para observar o comportamento da propagação dos ultrasons nos tijolos alterados. Os valores de $\Delta \mathrm{M}$ dos tijolos sãos são bastante díspares (17,09 (Lad-06) e 33,83 (Lad-11)). O valor maiss baixo de 17,09 corresponde à amostra Lad-06 previamente lavada con agua destilada e seca em estufa entre as medidas de ultrasons realizadas. As velocidades são apresentadas para as três direções perpendiculares às três faces dos tijolos ( $A, B$ e $C$ ), na Figura 15 e na Tabela 5 apresentam-se os valores de anisotropia total da velocidade de ultrasons. Ao iniciar o ensaio de envelhecimento em geral as amostras manifiestam uma inicial diminuição da velocidade de propagação das ondas ultrasônicas.

A amostra Lad-21 em geral, a longo dos dias de ensaio, aumenta a velocidade de propagação de ultrasons nas três direções $A, B$ e $C$, o que pode ser explicado com uma formação inicial de fissuras que, a partir do primeiro dia, foram progressivamente ocupadas por sais. Os valores de anisotropia total $(\Delta \mathrm{M})$ são coerentes uma vez que são calculados em relação à face $A$ do tijolo, assim que a amostra apresentou uma diminuição de $\Delta \mathrm{M}$ no 14 ㅇ dia quando registra-se um aumento da velocidade (Tabela 5).

A amosstra Lad-11 mantevo uma certa uniformidade dos valores de velocidade ao longo do ensaio, apresenta variações na velocidade de propagação das ondas perpendicular às faces $A$ e $B$, porém não acentuadas, em geral pode-se dizer constantes. Os valores de $\Delta M$ (Tabela 5) não apresentam grandes mudanças, são bastante aproximados o valor de $\Delta \mathrm{M}$ para o tijolo são. A curva da amostra Lad-03 apresenta pequenas variações porém em geral segue o comportamento da amostra Lad-11.

A amostra Lad-06, que foi sistematicamente lavada entre uma medida e outra, apresenta nos primeiros dez dias valores relativamente altos, depois tende a baixar e mantem-se mais ou menos constante, aproximando-se do comportamento da amostra Lad-11. Este comportamento pode ser explicado pela perda progressiva de sais junto de pequeno aumento da porosidade do tijolo. Além disso os valores de $\Delta \mathrm{M}$ apresentam uma diminuição até mesmo em relação ao valor de tijolo são. É importante considerar o caráter de cimentação dos sais, que segundo Carolina Cardell et al. (2008) pode favorecer um aumento das velocidades de propagação de ultrasons.
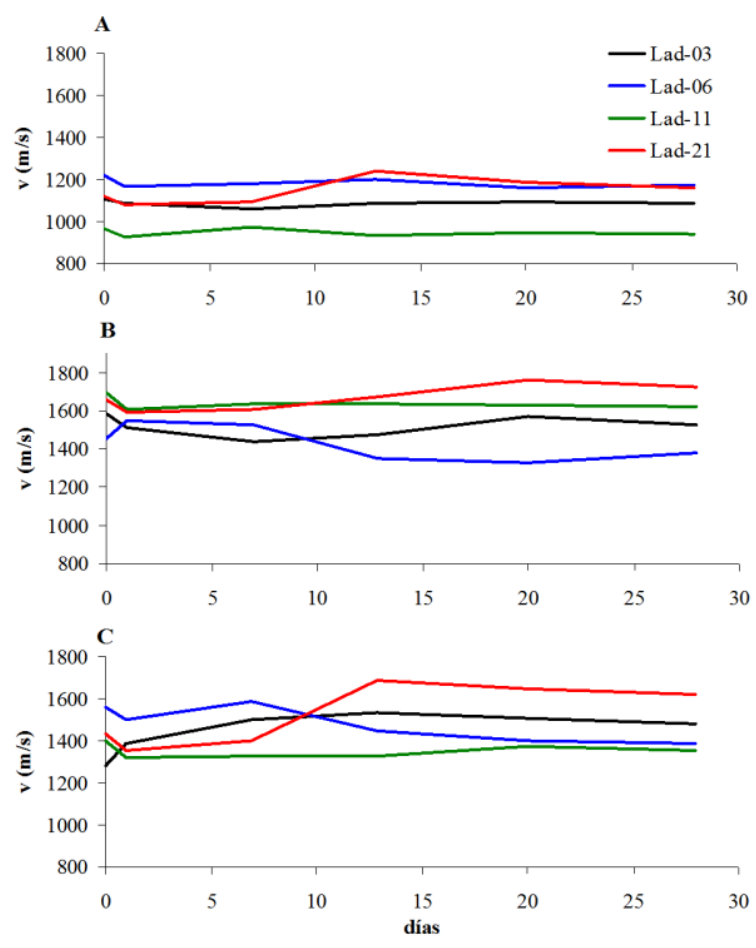

Figura 15. Variação da velocidade de propagação de ultrasons em tijolos alterados nos ensaios de alteração segundo as direções $A, B$ e C.

Tabela 5. Valores de anisotropia total de velocidade de propagação de ultrasons nas amostras de tijolo antes e depois dos ensaios de alteração ( $\Delta M$ em \%).

\begin{tabular}{|c|c|c|c|c|c|c|}
\hline Muestras & $\begin{array}{c}\mathbf{M M} \\
\text { Ladrillo } \\
\text { sano }\end{array}$ & $\begin{array}{c}\Delta \mathbf{M} \\
\text { 1ㅇ día }\end{array}$ & $\begin{array}{c}\Delta \mathrm{M} \\
700 \text { día }\end{array}$ & $\begin{array}{c}\Delta \mathrm{M} \\
14^{\circ} \text { día }\end{array}$ & $\begin{array}{c}\Delta \mathbf{M} \\
210 \text { día }\end{array}$ & $\begin{array}{c}\Delta \mathrm{M} \\
28^{\circ} \text { día }\end{array}$ \\
\hline LAD-03 & 20,61 & - & 24,88 & 25,37 & 26,10 & 25,17 \\
\hline LAD-06 & 17,09 & 21,45 & 21,80 & 12,77 & 13,54 & 13,42 \\
\hline LAD-11 & 33,83 & 33,00 & 30,88 & 33,30 & 32,96 & 33,23 \\
\hline LAD-21 & 25,04 & 24,12 & 24,52 & 23,91 & 27,77 & 27,93 \\
\hline
\end{tabular}

\subsubsection{Colorimetria}

Os parâmetros de cor obtidos para as amostras de tijolos sãos nos sistemas CIELab e $\mathrm{CIECH}$ são apresentados na Tabela 8. Percebe-se uma clara similaridade entre as amostras de tijolo, os valores de $L^{*}$ estão um pouco acima do valor médio de 50 . Os resultados de colorimetria para tijolos alterados revelaram algumas mudanças, em relação aos nao alterados, sobre tudo quando se refere à luminosidade das amostras, uma vez que se registrou um aumento do índice $L^{*}$ tanto nas amostras com os sais como naquelas que foram 
retirados, no primeiro e segundo ensaio de envelhecimento (Tabela 6). Os valores do índice $L^{*}$ para as amostras raspadas são mais altos, pois este processo favorece à superfície especular dos sais e assim reflete-se mais luz.

Os valores de cromaticidade também apresentam variações entre tijolos sãos e os submetidos aos ensaios de alteração, as amostras apresentam uma certa linearidade (Figura 16). Puede-se dizer que aquelas submetidas ao primeiro ensaio mostram uma migración gradual da cromaticidade para tons cinzas das amostras de tijolo alteradas. Por outro lado, as amostras utilizadas no segundo ensaio não apresentam esta mesma evolução, permanecendo todas em um campo aproximado de valores.

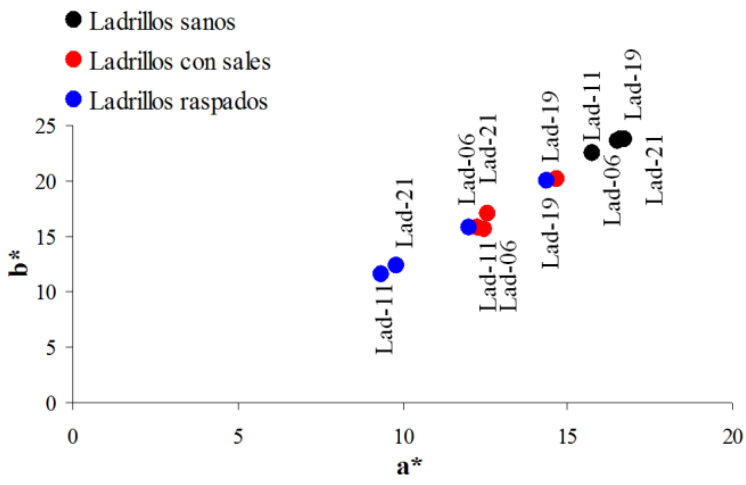

Figura 16. Diagrama de valores de cromaticidade $\left(a^{*} y b^{*}\right)$ para tijolos sãos e submetidos ao ensaio de alteração.

\section{CONCLUSÕES GERAIS}

O estudo da deterioração de materiais de construção por aerossóis marinhos em câmaras climáticas é importante, pois permite avaliar os níveis de deterioração que tais monumentos sofreriam construídos em áreas costeiras, e aquelhes que recebam a influencia deste ambiente. Vários autores estudaram edifícios históricos situados em zonas com influência de aerossóis marinhos, avaliando sua deterioração e os mecanismos de alteração (KUCHITSU et al., 1999, LOPEZ-ARCE et al., 2003, CARDELL et al., 2003,
LUBELLI et al., 2004, LARSEN, 2007 e SEBASTIAN et al., 2008).

Com o primeiro ensaio de alteração realizado nesta pesquisa pôde-se observar que mantendo constante a umidade relativa (U.R. $=70 \pm 5 \%$ ) não se desenvolve grande quantidade de cristais de sais. Entretando, no segundo ensaio, no qual a umidade relativa é variavel de $35 \pm 5 \%$ a $70 \pm 5 \%$, a cristalização de cloreto de sódio nas amostras de tijolo estudadas, foi mais abundante e mais prejudiacial. Conclusão: aquelhos tijolos localizados em monumentos ou áreas do mesmo nos quais existem variações de U.R. são mais suscetíveis para sofrer uma alteração por cristalização de sais. Estas variações de U.R. podem estar induzidas não somente pelas mudanças diurnas - noturnas de U.R., e sim também pela presença de brisas marinhas e correntes de ar formadas em determinados lugares abertos. Por isso, a "intervenção preventiva" de deterioração de materiais através do disenho das condições microclimáticas mais adequadas pode minimizar dano do objeto de arte.

Independentemente da composição da água do mar utilizada no ensaio, o único sal cristalizado é $\mathrm{NaCl}$. Os sais cristalizados nos tijolos apresentam variação no hábito (cristais cúbicos, cristal "hopper", cristal whiskers e alguns apresentam crescimento "espiral"), fato atribuído à variação da umidade relativa entre os dois ensaios realizados e, portanto, à umidade do substrato e à concentração da solução salina.

A deterioração dos tijolos submetidos à condições ambientais costeiras é principalmente de tipo físico, isto é, devido à pressão de cristalização de sais, uma vez que não foram observados fenômenos de dissolução de minerais nos tijolos. Como os cristais desenvolvem-se nos poros, ou como observou-se, em nosso caso, nos planos dos filossilicatos que compõe a matriz do tijolo, a tendência é progredir em seu crescimento e assim romper a estrutura do tijolo a escala microscópica.

Tabela 6. Resultados de colorimetria obtidos para as amostras de ladrillo antes e despois dos ensaios de alteração em câmara de spray salino ( $L^{*}=$ luminosidade; $a^{*}$ y $b^{*}=$ cromaticidade; $C^{*}=$ saturação; $H^{*}=$ tonalidade).

\begin{tabular}{|c|c|c|c|c|c|c|c|c|c|c|c|c|c|c|c|}
\hline 10 ENSAYO & \multicolumn{5}{|c|}{ LADRILLOS SANOS } & \multicolumn{5}{|c|}{ LADRILLOS CON SALES } & \multicolumn{5}{|c|}{ LADRILLOS RASPADOS } \\
\hline Índices & $\mathrm{L}^{*}$ & $a^{*}$ & $b^{*}$ & $\mathrm{C}^{*}$ & Ho & $\mathbf{L}^{*}$ & $a^{*}$ & $b^{*}$ & $\mathrm{C}^{*}$ & Ho & $\mathbf{L}^{*}$ & $a^{*}$ & $\mathbf{b}^{*}$ & $\mathrm{C}^{*}$ & Ho \\
\hline LAD-06 & 59,70 & 16,54 & 23,56 & 28,78 & 55,0 & 64,36 & 12,49 & 15,58 & 19,96 & 51,3 & 65,18 & 12,01 & 15,73 & 19,79 & 52,7 \\
\hline LAD-11 & 58,17 & 15,74 & 22,56 & 27,50 & 55,1 & 65,23 & 12,28 & 15,74 & 19,96 & 52,1 & 67,2 & 9,37 & 11,64 & 14,94 & 51,2 \\
\hline LAD-19 & 58,06 & 16,64 & 23,71 & 28,96 & 55,0 & 60,23 & 14,66 & 20,13 & 24,9 & 54 & 62,23 & 14,35 & 19,94 & 24,56 & 54,3 \\
\hline LAD-21 & 59,68 & 16,74 & 23,79 & 29,08 & 54,9 & 63,65 & 12,58 & 16,98 & 21,13 & 53,5 & 67,41 & 9,83 & 12,32 & 15,76 & 51,5 \\
\hline 2 ENSAYO & \multicolumn{5}{|c|}{ LADRILLOS SANOS } & \multicolumn{5}{|c|}{ LADRILLOS CON SALES } & \multicolumn{5}{|c|}{ LADRILLOS RASPADOS } \\
\hline Índices & $\mathrm{L}^{*}$ & $a^{*}$ & $b^{*}$ & $c^{*}$ & Ho & $\mathrm{L}^{*}$ & $a^{*}$ & $\mathbf{b}^{*}$ & $\mathrm{C}^{*}$ & Ho & $\mathrm{L}^{*}$ & $a^{*}$ & $b^{*}$ & $\mathrm{C}^{*}$ & Ho \\
\hline LAD-03 & 58,69 & 15,56 & 22,35 & 27,23 & 55,2 & 63,25 & 12,65 & 15,4 & 19,92 & 50,63 & 64,6 & 13,11 & 16,83 & 21,33 & 52,2 \\
\hline LAD-14 & 57,70 & 15,77 & 22,35 & 27,35 & 54,8 & 60,4 & 16,23 & 22,89 & 28,06 & 54,7 & 61,74 & 16,59 & 24,53 & 29,6 & 59,3 \\
\hline
\end{tabular}


Os filossilicatos presentes nos tijolos estudados são "zonas de fraqueza" onde inicia-se e propaga a cristalização de $\mathrm{NaCl}$. Sua estrutura em lâminas favorece além do mais a ruptura do tijolo segundo planos.

A porosimetria por injeção de mercúrio mostrou que os tijolos submetidos a ensaios de alteração por aerossóis marinhos sofreram uma diminuição da porosidade aberta devido à cristalização dos sais em poros e orificios (ocos). Ao limpar as amostras com água destilada foram observadas duas situações: 1) o aumento da porosidade de $6,85 \%$ e 2) a diminuição da porosidade de $6,74 \%$. Este segundo caso pode ser explicado pelo efeito de cimentação dos sais, que também interfere nos valores de velocidade de propagação de ultrasom. Em qualquer caso, a diminuição da porosidade aberta não leva a uma melhora das características mecânicas do tijolo.

A análise colorimétrica revela que a presença de eflorescências supõe uma diminuição de luminosidade e tonalidade em relação ao material são. Assim mesmo produz-se uma variação dos valores cromáticos $a^{*}$ e $b^{*}$ tal que as amostras alteradas tornam-se mais cinzas, com um consequente efeito estético não desejado. É de grande importância enfatizar o cuidado que se deve ter com os métodos de limpeza utilizados para a retirada dos sais dos materiais de construção danificados por eflorescências, pois raspar altera a luminosida da final, aumentando-a.

$\mathrm{Na}$ deterioração dos tijolos é fundamental a presença e disposição das argilas em relação à superfície exposta do mesmo, isto é, em relação a seu arranjo, horizontal oi vertical, assim como a superfície do tijolo exposta na edificação.

\section{REFERÊNCIAS BIBLIOGRÁFICAS}

ALLABY, A. \& ALLABY, M. Dictionary of Earth Sciences. Oxford University Press. 1999. 622p.

ARNOLD, A. \& ZEHNDER, K. Salt weathering on Monuments. In: First International Symposium on the Conservation of Monuments in the Maditerranean Basin, ed. F. Zezza. Brescia: Grafo. 1990, 31-58.

ASTM-B-117-73. Standard Practice for Operating Salt Spray Apparatus. 1973. 8p.

BARBOSA, R. C. O. Evaluación del deterioro de ladrillos por aerosoles marinos. 2008. Monografía (Master Geología). Departamento de Mineralogía y Petrología, Universidad de Granada, Granada-ES, 2008. 50p.

BOUDREAU, E. H. Making the adob brick. Berkeley, CA. 1971. 88p.

CARDELL, C. Cristalización de sales en calcarenitas: aplicación al Monasterio de San Jerónimo. (Doctoral Tesis). Departamento de Mineralogía y Petrología, Universidad de Granada. 1998.

CARDELL, C.; RIVAS, T.; MOSQUERA, M.J.; BIRGINIE, J.M.; MOROPOULOU, A.; PRIETO, B.; SILVA, B. \& VAN GRIEKEN, R.. Patterns of damage in igneous and sedimentary rocks under conditions simulating sea-salt weathering. Earth Surf. Process. Landforms 28 (2003) p. 1-14.
CARDELL, C.; DELALIEAUX, F.; ROUMPOPOULOS, K.; MOROPOULOU, A.; AUGER, F. \& VAN GRIEKEN, R. Salt induced decay in calcareous stone monuments and buildings in a marine environment in SW France. Construction and Building Materials. 17 (2003) p. 1165-179.

CARDELL, C.; BENAVENTE， D. \& RODRÍGUEZ-GORDILLO, J. Weathering of limestone building material by mixed sulfate solutions. Characterization of stone microstructure, reaction products and decay forms. Materials Characterization. 59 (10) (2008) p. 1371-1385.

CHABAS, A.; JEANNETTE, D. \& LEFÈVRE, R.A.. Crystallization and dissolution of airborne sea-salts on weathered marble in a coastal environment at Delos (Cyclades-Greece). Atmospheric Environment. 34 (2000) p. 219-234.

CHAROLA, A. E. Salts in the deterioration of porous materials: an overview. Journal of the American Institute for Conservation. 39 (2000) p. 327-343.

CLARK, B. H. \& PEACOR, D. R. Pyrometamorphism and partial melting of shales during combustion metamorphism: mineralogical, textural, and chemical effects. Contributions to Mineral Petrology. 112 (1992) p. 558-568.

CULTRONE, G. Estudio mineralógico-petrográfico y físicomecánico de ladrillos macizos para su aplicación en intervenciones del Patrimonio Histórico. (PhD Tesis). Departamento de Mineralogía y Petrología, Universidad de Granada. 2001. 293p.

CULTRONE, G. Ladrillos. Programa de normalización de estudios previos aplicado a bienes inmuebles. En: PH Cuadernos 19. Instituto Andaluz del Patrimonio Histórico. 2006 p. 146-159.

DOEHNE, E.. Salt Weathering: A Selective review. In: The Geological Society of London, Special Publication: Geomaterials, weathering phenomena, conservation strategies and case studies. 2003 p: 205-219.

EVANS, I.S. Salt crystallization and rock weathering: a review. Reveu de Géomorphologie Dynamique XIX (4) (1969) p. 153177.

FABBRI, B. I metodi della mineralogia nella ricerca sui material ceramici, con particolare riferimento a quelli avanzati. Mineral. et Petrographica Acta, v.31 (1988) p.179-188.

GOMEZ-HERAS, M. \& FORT, R. Patterns of halite $(\mathrm{NaCl})$ crystallisation in building Stone conditionned by laboratory heating regimes. Environmental Geology. 52 (2007) p. 259267.

GRAPES, H. Melting and thermal reconstitution of pelitic xenolits, Wher Volcano, East Eifel, West Germany. Journal Petrology. 27 (1986) p. 343-396.

KORNMANN, M. \& CTTB. Clay bricks and roof tiles, manufacturing and properties. Soc. Industries minières, Paris. 2007.

KUCHITSU, N.; ISHIZAKI, T. \& NISHIURA, T. Salt weathering of the brick monuments in Ayutthaya, Thailand. Engineering Geology. 55 (1999) p. 91-99.

LARSEN, P. K. The salt decay of medieval bricks at a vault in Barup Church, Denmark. Environmental Geology. 52 (2007) p. 375383.

LÓPEZ-ARCE, P.; GARCIA-GUINEA, J.; GRACIA, M. \& OBIS, J. Bricks in historical buildings of Toledo City: characterisation and restoration. Mater. Charact. 50 (2003) p. 59-68.

LUBELLI, B.; VAN HEES, R.P. J. \& GROOT, C.J.W.P. The role of sea salts in the occurrence of different damage mechanisms and decay patterns on brick masonry. Construction and Building Materials. 18 (2003) p. 119-124. 
OTHMER, K. Encyclopedia of Chemical Processes. Jogn Wiley \& Sons, 1978. pg.

PLIEGO RL-88. Pliego general de condiciones para le recepción de ladrillos cerámicos en las obras de construcción. Ministerio de Obras Públicas, Transporte y Medio Ambiente. Madrid, 1988.

RAPP, G.. Archeomineralogy. Springer - Verlag. Berlin Heidelberg, 2002. 326p.

RICCARDI, M. P.; MESSIGA, B \& DUMINUCO, P. An approuch to the dynamics of clay firing. Appl Clay Sci., 15 (1999) p. 393409 .

RIVAS, T.; PRIETO, B.; SILVA, B. \& BIRGINIE, J.M. Weathering of granitic rocks by chlorides: effect of the nature of the solution on weathering morphology. Earth Surf. Process. Landforms. 28 (2003) p. 425-436.

RODRÍGUEZ-NAVARRO, C. \& DOEHNE, E. Salt weathering: influence of evaporation rate, supersaturation and crystallization pattern. Earth surface Proc. and Land. 23 (3) (1999) p. 191-209.

SEBASTIÁN, E.; CULTRONE, G.; BENAVENTE, D.; FERNÁNDEZ, L. L.; ELERT, K. \& RODRÍGUEZ-NAVARRO, C. Swelling damage in clay-rich sandstone used in the Church of San Mateo in Tarifa (Spain). Journal of Cultural Heritage. 9 (1) (2008) p. 66-76.

SCHERER, G. W. Theory of Drying. Jour. of the American Ceramic Society. 73 (1) (1990) p. 3-14.

UNE 67019 EX/96. Ladrillos cerámicos de arcilla cocida. Definiciones, clasificaciones y especificaciones. Norma española experimental AENOR, Madrid, 1996. 9p.
UNE-EN 772-5/05. Métodos de ensayo de piezas para fábrica de albañilería. Parte 5: determinación del contenido en sales solubles activas en las piezas de arcilla cocida para albañilería. Norma española experimental AENOR, Madrid, $12 p$.

UNE-EN 13755. Métodos de ensayo para piedra natural. Determinación de la absorción de agua a presión atmosférica. Norma española experimental AENOR, Madrid, 2002. 10p.

UNE-EN 14147. Métodos de ensayo para la piedra natural. Determinación de la resistencia al envejecimiento por niebla salina. Norma española experimental AENOR, Madrid, 2004. $11 \mathrm{p}$.

ZEHNDER, K. \& ARNOLD, A. Crystal growth in salt efflorescence. Journal of Crystal Growth. 97 (1989) p. 513-521

Contribuição ao

1ํ. Simpósio Brasileiro de Caracterização e Conservação da Pedra 14 a 16 de dezembro de 2016, Congonhas - MG

\section{Nota:}

É de responsabilidade da comissão editorial do Simpósio a revisão gramatical, ortográfica, de citações e referências bibliográficas. As normas de submissão podem se diferenciar das desta revista. 